\title{
Introduction to the Special Issue "High Power THz Technologies Opened by High Frequency Gyrotrons"
}

\author{
Toshitaka Idehara
}

Received: 8 May 2012 / Accepted: 11 May 2012 /

Published online: 22 May 2012

(C) Springer Science+Business Media, LLC 2012

At the present, study on $\mathrm{THz}$ technologies is advancing world-widely. However, in almost all cases, those are quite low power technologies. Usually, the output power of the used radiation sources is lower than $1 \mathrm{~mW}$. Although such low power technologies for $\mathrm{THz}$ spectroscopy are still opening new development of $\mathrm{THz}$ region, high power technologies even in $\mathrm{THz}$ region will be important in near future. I think gyrotrons can open such important technologies. Their applications to high power $\mathrm{THz}$ technologies have begun already for active $\mathrm{THz}$ spectroscopy, new medical technologies, material science, bioscience, etc. On the basis of such a present status, we have organized this special issue of JIMT as a timely planning. The title is "High Power THz Technologies Opened by High Frequency Gyrotrons".

This issue consists of an Introduction, three review papers and five original papers as follows,

The contents

1. Introduction to the Special Issue "High Power THz Technologies Opened by High Frequency Gyrotrons"

2. Development and Applications of High Frequency Gyrotrons in FIR FU Covering the sub-THz to THz Range (Review paper)

3. Low-Loss Transmission Lines for High-Power Terahertz Radiation (Review paper)

4. Gyrotron Development for High Power Technologies in IAP RAS (Review paper)

5. Development of a Compact Sub-THz Gyrotron FU CW CI for Application to High Power THz Technologies

6. Application of Continuously Frequency-Tunable 0.4 THz Gyrotron to Dynamic Nuclear Polarization for $600 \mathrm{MHz}$ Solid-State NMR

7. Development of DNP-Enhanced High-Resolution Solid-State NMR System for the Characterization of the Surface Structure of Polymer Materials

8. Direct measurement of Positronium HyperFine Structure: A New horizon of Precision Spectroscopy using Gyrotrons

T. Idehara $(\square)$

University of Fukui, FIR Center, Fukui, Japan

e-mail: idehara@fir.u-fukui.ac.jp 
9. X-Ray Detected Magnetic Resonance at Sub-THz Frequencies Using a High Power Gyrotron Source

All of these papers are presenting quite new technologies opened only by high power $\mathrm{THz}$ radiation sources like Gyrotrons. In the case, the output power is ranged from several watt to several tens kilowatts even in sub- $\mathrm{THz}$ to $\mathrm{THz}$ region. I hope this special issue will pull forward the development of $\mathrm{THz}$ region and contribute to open many high power $\mathrm{THz}$ technologies which will achieve to develop both many research fields and many industrial technologies.

May 10, 2012 